\title{
Chronic lymphocytic leukemia and Second Primary Malignancies: A Relationship Revisited
}

Sir,

Chronic lymphocytic leukemia (CLL), the most commonly diagnosed leukemia globally, generally affects older persons with median survival being in excess of 10 years. $^{[1]}$ Present-day treatment options achieve good responses, thereby improving long-term survival. However, not widely recognized is the fact that these patients may have rather an increased susceptibility to second primary malignancies (SPMs) among other issues. ${ }^{[2]}$ Indeed, a 20\% greater risk of occurrence of any SPM has been found in studies comparing these patients to the U. S. general population. This increased risk has been seen for both solid as well as hematological malignancies. ${ }^{[3]}$ The probable causes for such observation could be genetic susceptibility, common risk factors, CLL-associated immune dysfunction, and possibly the effect of chemotherapy.

\section{Characterization of Second Primary Malignancies in Chronic Lymphocytic Leukemia}

Solid SPMs outnumber hematopoietic malignancies, as reported in different large studies. As per one of these population-based studies, lung cancer and melanoma attributed the most to the excess risk of SPMs, $59 \%$ and $31 \%$, respectively. The highest risk of SPMs was seen within 2-5 months of CLL diagnosis, diminishing significantly after 6 months and stabilized thereafter. Even after 10 years of diagnosis of CLL, patients still had a $11 \%$ higher risk of SPMs in comparison to the U. S. general population. ${ }^{[3]}$ In a similar study of long-term CLL survivors, defined as having survived 10 years or more, nonmelanoma skin cancer was the most common SPM. Solid-organ malignancies again outnumbered hematologic malignancies with prostate, breast, lung, and cervical cancers being prominent and leukemia being the most common hematologic malignancy, translating to a cumulative frequency of $31 \%$ SPMs. Few of the predictors for the development of SPM were older age, male gender, and low platelet counts. Survival of the patients is also compromised in the patients with SPM, as reported to be 16.2 months in the above study which was in stark contrast to 22.9 years in the patients without second primary malignancy $\cdot^{[4]}$

Putative causes of Development of Second Primary Malignancies in Chronic Lymphocytic Leukemia

1. Age: A long survival in the patients of CLL is a pointer toward age being one of the most important shared risk factors. The above two studies ${ }^{[3,4]}$ after multivariate analysis suggested the same.
2. Genetic predisposition: Aggressive genetic risk factors of CLL may predict an increased risk for second malignancies as well, as shown in a study from MD Anderson Cancer Center. Deletion 17p, 6q deletion, or 11q deletion and/or trisomy 12 conferred an increased risk in comparison to low-risk or normal cytogenetic ${ }^{[5]}$

3. Immunodysregulation: Immunodysregulation is a known attribute of CLL with hitherto unknown mechanisms. As seen in clinical practice, deficient immunoglobulins and a predisposition to infection point to a dysfunctional adaptive immunity. T-cell repertoire is altered with a raised CD8 T-cell count and a reversal of CD4-to-CD8 ratio, present early and keeps becoming more apparent with the progression of disease ${ }^{[6]}$

4. Effect of chemotherapy: Chemotherapeutic agents and regimens with their effect on DNA and hematopoietic stem cells may well contribute to the development of SPMs. However, risk for solid malignancies is very low in comparison to an elevated risk for hematologic malignancies $^{[7]}$

5. Others: male gender, low platelet counts, and high $\beta 2$-microglobulin levels have been found to be predictors in many retrospective studies ${ }^{[3,4]}$

\section{Newer Agents and Second Primary Malignancies}

Bruton tyrosine kinase (Btk) inhibitors such as ibrutinib and acalabrutinib are approved now for first- as well as second-line treatment of CLL. They are believed to improve immunity in the patients of CLL. ${ }^{[8,9]}$ However, these agents are also being associated with increased risk of SPMs, particularly lung cancer and nonmelanoma skin cancer. $^{[10]}$

\section{Screening of Chronic Lymphocytic Leukemia Survivors for Second Primary Malignancies}

Given the high risk of SPMs in the CLL survivors, it is imperative to frame a clear guideline for their follow-up. Screening for nonmelanoma skin, breast, cervical, colon, and prostate cancers is recommended. ${ }^{[1]}$ Annual dermatologic skin screening is recommended for nonmelanoma skin cancer and standard screening is recommended for other cancers. A clinician should do a meticulous examination of all these patients, particularly the long-term survivors.

\section{Conclusion}

Second primary malignancies are common in the patients of CLL. Nonmelanoma skin, lung, breast, prostate, cervical, and colon cancers are the most prominent cancers in these patients. Development of a second primary malignancy 
drastically reduces survival. Long-term survivors of CLL must therefore be screened for all these cancers.

\section{Financial support and sponsorship}

Nil.

\section{Conflicts of interest}

There are no conflicts of interest.

\section{Amarendra Amar}

Department of Medical Oncology, Indraprastha Apollo Hospital, New Delhi, India

Address for correspondence: Dr. Amarendra Amar, D-134, Ground Floor, Pocket-D, Sarita Vihar, New Delhi - 111 076,

India.

E-mail:amar.jha82@gmail.com

Submitted: 06-Jun-2020

Revised: 25-Jul-2020

Accepted: 05-Oct-2020

Published: 29-Oct-2020

\section{References}

1. Siegel RL, Miller KD, Jemal A. Cancer statistics, 2018. Cancer $\mathrm{J}$ Clin 2018;68:7-30.

2. Tam CS, Keating MJ. Chemoimmunotherapy of chronic lymphocytic leukemia. Nat Rev Clin Oncol 2010;7:521-32.

3. Kumar V, Ailawadhi S, Bojanini L, Mehta A, Biswas S, Sher T, et al. Trends in the risk of second primary malignancies among survivors of chronic lymphocytic leukemia. Blood Cancer J 2019;9:75.

4. Falchi L, Vitale C, Keating MJ, Lerner S, Wang X, Elhor Gbito KY, et al. Incidence and prognostic impact of other cancers in a population of long-term survivors of chronic lymphocytic leukemia. Ann Oncol 2016;27:1100-6.

5. Tsimberidou AM, Wen $\mathrm{S}$, McLaughlin $\mathrm{P}$, O'Brien $\mathrm{S}$, Wierda WG, Lerner $\mathrm{S}$, et al. Other malignancies in chronic lymphocytic leukemia/small lymphocytic lymphoma. J Clin
Oncol 2009;27:904-10.

6. Forconi F, Moss P. Perturbation of the normal immune system in patients with CLL. Blood 2015;126:573-81.

7. Benjamini O, Jain P, Trinh L, Qiao W, Strom SS, Lerner S, et al. Second cancers in patients with chronic lymphocytic leukemia who received frontline fludarabine, cyclophosphamide and rituximab therapy: Distribution and clinical outcomes. Leuk Lymphoma 2015;56:1643-50.

8. Byrd JC, Furman RR, Coutre SE, Burger JA, Blum KA, Coleman $\mathrm{M}$, et al. Three-year follow-up of treatment-naïve and previously treated patients with CLL and SLL receiving single-agent ibrutinib. Blood 2015;125:2497-506.

9. Byrd JC, O'Brien S, James DF. Ibrutinib in relapsed chronic lymphocytic leukemia. N Engl J Med 2013;369:1278-9.

10. Bond DA, Huang Y, Fisher JL, Ruppert AS, Owen DH, Bertino EM, et al. Second cancer incidence in CLL patients receiving BTK inhibitors. J Clin Oncol 2019;37:15_Suppl, 7511`.

11. Chronic Lymphocytic Leukemia/Small Lymphocytic Lymphoma, Version 4; 2020, National Comprehensive Cancer Network. Available from: www.nccn.org. [Last updated on 2020 Aug 29].

This is an open access journal, and articles are distributed under the terms of the Creative Commons Attribution-NonCommercial-ShareAlike 4.0 License, which allows others to remix, tweak, and build upon the work non-commercially, as long as appropriate credit is given and the new creations are licensed under the identical terms.

\begin{tabular}{|l|l|}
\hline \multicolumn{2}{|c|}{ Access this article online } \\
\hline Quick Response Code: & Website: \\
& www.ijmpo.org \\
\cline { 2 - 2 } & Dol: \\
\hline
\end{tabular}

How to cite this article: Amar A. Chronic lymphocytic leukemia and second primary malignancies: A relationship revisited. Indian J Med Paediatr Oncol 2020;41:787-8 